\title{
PENGEMBANGAN PEMBELAJARAN E-LEARNING MATA KULIAH PTM/JALAN RAYA PENDIDIKAN VOKASIONAL KONSTRUKSI BANGUNAN FAKULTAS TEKNIK UNIVERSITAS NEGERI JAKARTA
}

\author{
Abdul Azis Mubarok ${ }^{1}$, Riyan Artbur', Santoso Sri Handoyo ${ }^{3}$ \\ ${ }^{1}$ Alumni PTB FT UNJ, abdulazizmubarok29@gmail.com \\ ${ }^{2}$ Dosen PVKB FT UNJ, arthur@uni.ac.id \\ ${ }^{3}$ Dosen PVKB FT UNJ, santoso handoyo@unj.ac.id
}

\begin{abstract}
Abstrak
Penelitian ini merupakan penelitian pengembangan yang bertujuan untuk mengembangkan pembelajaran khususnya dalam bentuk E-Learning pada mata kuliah PTM/Jalan Raya.

Penelitian pengembangan ini merupakan metode penelitian Research and Development dengan model penelitian Borg and Gall. Penelitian ini pada dasarnya dilakukan melalui lima tahap utama, yaitu Penelitian dan pengumpulan informasi (Research and Information Collecting), Perencanaan (planning), pengembangan bentuk awal produk (develop preliminary form of product), uji lapangan dan revisi produk (filed testing and product revision), revisi produk akhir (final product revision) dan proses penyebaran dan impementasi (disseminate and implementation). Penelitian ini sampai tahap Revisi produk akhir karena hanya mengembangkan pembelajaran E-Learning. Penelitian ini menggunakan angket sebagai alat untuk menguji kelayakan melalui validasi ahli instruksional, ahli media dan ahli materi serta melihat tanggapan dari mahasiswa.

Hasil pengembangan didapatkan produk pembelajaran E-Learning Penilaian oleh dosen ahli instruksional menggunakan skala likert skor 1-4 mendapatkan nilai 2,5 yang dikategorikan "layak". Penilaian oleh dosen ahli media dan ahli materi menggunakan skala guttman skor 0-1 mendapatkan nilai 0,83 yang dikategorikan "layak" untuk penilaian ahli media. Penilaian dosen ahli materi mendapatkan nilai 0,86 yang dikategorikan "layak".
\end{abstract}

Kata kunci : Desain instruksional, E-Learning, PTM/Jalan Raya

\section{DEVELOPMENT OF E-LEARNING FOR PTM/HIGHWAY COURSES IN VOCATIONAL EDUCATION STUDY PROGRAM FOR BUILDING CONSTRUCTION FACULTY OF ENGINEERING STATE UNIVERSITY OF JAKARTA}

\author{
Abdul Azis Mubarok, Riyan Artbur ${ }^{2}$, Santoso Sri Handoyo ${ }^{3}$ \\ ${ }^{1}$ Alumni of PVKB FT UNJ, abdularizmubaroksipil14@mabasiswa.unj.ac.id \\ ${ }^{2}$ Lecturer of PVKB FT UNJ, arthun@,unj.ac.id \\ ${ }^{3}$ Lecturer of PVKB FT UNJ, santoso handoyo@unj.ac.id
}

\begin{abstract}
This research is a development research that aims to develop learning especially in the form of ELearning in PTM / highway courses.

This development research is a Research and Development research method with Borg and Gall research model. This research is basically carried out through five main stages, namely Research and information gathering (Research and Information Collecting), planning, developing preliminary form of product,
\end{abstract}


field testing and product revision (filed testing and product revision), final product revision and disseminate and implementation processes. This research is only up to the Revision of the final product because it only reaches the development of E-Learning learning. This study uses a questionnaire as a tool to test the feasibility through validation of instructional experts, media experts and material experts and see respon from student

The results of the development obtained E-Learning learning assessment products by instructional expert lecturers using a Likert scale score 1-4 get a score of 2.5 which is categorized as "feasible". Assessment by media expert lecturers and material experts using the Guttman scale score of 0-1 gets a value of 0.83 which is categorized as "feasible" for the assessment of media experts. The assessment of material expert lecturers gets a value of 0.86 which is categorized as "feasible".

Keywords: Instructional design, E-Learning , PTM/Highway.

\section{Pendahuluan}

Paradigma pendidikan mengalami perubahan sedemikian pesat dikarenakan oleh berkembanganya ilmu pengetahuan teknologi dan kependidikan. Pendidikan dalam prosesnya tidak terlepas dari pengajaran atau pembelajaran, istilah pengajaran dipandang kurang tepat sebab menempatkan pengajar sebagai pelaku utama dan lebih dominan dalam proses belajar-mengajar, (Suparman.A, 2012:9) hal ini menyebabkan peserta didik pasif, hanya menjadi pendengar yang baik, tertib dan senang "disuapi" materi pelajaran

"Pendidikan adalah pendewasan peserta didik agar dapat mengembangkan bakat, potensi dan ketrampilan yang dimiliki dalam menjalni kehidupan, oleh karena itu sudah seharusnya pendidikan didesain guna memberikan pemahaman serta meningkatkan prestasi belajar peserta didik". (Daryanto, 2011:1)

Prestasi belajar sering dikaitkan dengan permasalahan belajar peserta didik dalam memahami materi. Permasalahan belajar tersebut terjadi dimungkinkan karena faktor belajar siswa yang kurang efektif atau juga bisa karena materi pembelajaran yang disampaikan kurang menarik. Karena pendidikan adalah langkah fundamental dalam kehidupan setiap orang, kita harus meningkatkan popularitas, ketersediaan, dan kenyamanannya bagi semua orang (Andreicheva \& Latypov, 2015:629) Penggunaan teknologi untuk pendidikan menjadi solusi untuk menyelesaikan masalah tersebut, mengembangkan pembelajaran sebagai upaya meningkatkan prestasi belajar.

Pemanfaaatan teknologi yang baik dapat menjadi salah satu cara untuk mewujudkan pembelajaran yang variatif dan kreatif. perkembangan teknologi pada dekade ini menunjukkan peningkatan yang signifikan, hal tersebut dapat membawa dampak positif dan dampak negatif bagi masyarakat secara luas. Penerapan teknologi pada berbagai bidang ilmu sudah banyak dilakukan termasuk pada bidang pendidikan. tetapi pemanfaatannya dirasa masih belum maksimal.

Pemanfaatan teknologi juga menjadi ciri khas revolusi industri 4.0 yang saat ini menjadi perhatian pemerintah untuk mengadapi era globalisasi yang berkembang semakin cepat. Berbagai kompetensi dipersiapkan salah satu upayanya yaitu dengan meningkatkan kegiatan pembelajaran yang lebih mudah dan efisien dengan memanfaatkan teknologi. Internet saat ini menjadi sektor yang berkembang dengan cepat, Internet memiliki banyak aplikasi yang berguna di bidang komersial, sosial, dan pendidikan. Dalam skenario hari ini, E-Learning juga merupakan salah satu aplikasi yang berguna di dunia internet. ELearning telah mencapai kemajuan di berbagai bidang seperti sistem E-Learning adaptif. (Srivastava \& Haider, 2017:178)

E-Learning merupakan salah satu pembelajaran yang dapat digunakan untuk mempermudah kinerja dalam mengajar. ELearning adalah pembelajaran yang paling 
efisien dan dekat dengan siswa. Jika media ini dikemas dengan baik, unik dan serius maka E-Learning tidak hanya sebagai media pembelajaran, tetapi juga bisa sebagai media informasi, hiburan dan pendidikan (Daryanto, 2011:168)

E-Learning dapat didefinisikan
sebagai ilmu pembelajaran tanpa
mengounakan kertas cetak materi
instruksional (Goyal, 2012). Pembelajaran E-Learning merupakan pembelajaran yang fleksibel karena pengajar dan pembelajar dapat mengakses tanpa terhalang waktu dan tempat. Saat ini banyak lembaga pendidikan seperti perguruan tinggi lain yang sudah mulai menggunakan E-Learning untuk mendukung sistem pendidikan. untuk dapat mendukung sistem pendidikan di Indonesia dengan maksimal, maka praktisi pendidikan harus mampu mengembangkan dan mengelola E-Learning dengan baik. Salah satu mata kuliah yang efektif mengembangkan dan mengelola E-Learning adalah PTM/Jalan Raya.

Dampak positif yang dapat dirasakan secara nyata dari kemajuan teknologi dalam bidang pendidikan adalah fasilitas dan sumber belajar yang bervariasi, salah satunya adalah E-Learning. E-Learning atau elektronik learning adalah pembelajaran yang memanfaatkan teknologi informasi dan komunikasi ELearning dalam praktiknya selalu memanfaatkan alat elektronik untuk menyampaikan materi, mengumpulkan tugas, diskusi, kuis dan mengetahui hasil nilai evaluasi. Penerapan E-Learning belum maksimal diterapkan di Universitas Negeri Jakarta (UNJ) khususnya pada jurusan Pendidikan Vokasional Konstruksi Bangunan (PVKB) Fakultas Teknik (FT).

Pembelajaran pada beberapa mata kuliah program studi pendidikan vokasional konstruksi bangunan belum mengunakan pembelajaran yang lain. Berdasarkan hasil survei analisis kebutuhan, mengenai pembelajaran mata kuliah PTM/Jalan Raya kepada 24 mahasiswa yang telah mengikuti mata kuliah PTM/Jalan Raya menunjukan $96 \%$ berpendapat bahwa kegiatan perkuliahan PTM/Jalan Raya membutuhkan pembelajaran lain yang interaktif dan mudah seperti E-Learning

Mahasiswa PVKB pada umumnya melakukan sistem pembelajaran dalam kelas, yang kebanyakan mahasiswa menjalani pembelajaran hanya terbatas di ruang kelas sedikit sekali mahasiswa yang melakukan pembelajaran diluar kelas. Untuk itu E-Learning akan mendorong mahasiswa menggunakan pembelajaran berbasis online dengan kemudahan yang dapat diakses kapanpun dan dimanapun.

Materi yang terdapat pada mata kuliah PTM/Jalan Raya dimungkinkan dapat dijadikan materi mandiri sehingga pembuatan pembelajaran E-Learning yang lebih interaktif ini diharapkan dapat membuat mahasiswa lebih aktif dan mandiri dalam pembelajaran, sarana prasarana sudah mendukung penggunaan E-Learning

Berdasarkan pada masalah yang telah dipaparkan, menarik untuk dilakukan penelitian tentang pengembangan pembelajaran E-Learning pada mata kuliah PTM/Jalan Raya program studi S1 pendidikan vokasional konstruksi bangunan di Fakultas Teknik Universitas Negeri Jakarta. Penggunaan pembelajaran yang telah dikembangkan ini, diharapkan dapat membantu dosen dalam menyampaikan teori atau konsep dasar dari mata kuliah PTM/Jalan Raya sehingga dapat menarik mahasiswa dalam memahami materi yang disampaikan dosen yang bersangkutan dan dapat meningkat hasil belajar mahasiswa pada mata kuliah tersebut

\section{Identifikasi Masalah}

Berdasarkan uraian latar belakang yang telah dikemukakan sebelumnya, terdapat beberapa permasalahan yang dapat diidentifikasi sebagai berikut:

1. Bagaimana penyampaian materi dalam kegiatan pembelajaran?

2. Bagaiman pengembangan pembelajran E-Learning mata kuliah PTM/Jalan Raya ? 
3. Apakah mahasiswa terbiasa dengan pembelajaran E-Learning?

4. Apakah E-Learning PTM/Jalan Raya mudah digunakan?

\section{Pembatasan Masalah}

Menurut identifikasi masalah di atas dan agar pokok bahasan tidak melebar dan menyimpang dari topik utamanya, maka dalam penyusunan skripsi ini, lingkup pembahasannya meliputi:

1. Pengembangan pembelajaran E-Learning pada mata kuliah PTM/Jalan Raya

2. Pengembangan pembelajaran PTM/Jalan Raya dilakukan di program studi PVKB UNJ

3. Penelitian ini dilakukan pada mahasiswa yang sedang mengikuti mata kuliah PTM/Jalan Raya semester genap tahun ajaran 2017/2018 (semester 108)

4. Pengembangan pembelajaran E-Learning menggunakan software moodle

5. Pembelajaran E-Learning tidak mencakup materi perencanaan

\section{Rumusan Masalah}

Berdasarkan identifikasi masalah dan pembatasan masalah, maka masalah dapat dirumuskan sebagai berikut: Bagaimana pengembangan pembelajaran ELearning pada mata kuliah PTM/Jalan Raya program studi S1 PVKB FT UNJ

\section{Kegunaan Hasil Penelitian}

Manfaat dari penelitian ini diharapkan pengembangan E-Learning mata kuliah PTM/Jalan Raya untuk meningkatkan pengetahuan tentang pengembangan pembelajaran E-Learning PTM/Jalan Raya bagi mahasiswa dan dapat dijadikan sebagai masukan, referensi perangkat pembelajaran E-Learning bagi dosen pengajar Selain itu, dapat menjadi salah satu pilihan pembelajaran untuk mata kuliah PTM/Jalan Raya.

Sebagai inspirasi atau ide baru untuk mata kuliah lain agar membuat pembelajaran E-Learning serupa PTM/Jalan
Raya yang dapat meningkatkan motivasi, minat, dan hasil belajar mahasiswa .

\section{Tinjauan Pustaka}

\section{Desain Instruksional}

Menurut Kamus Besar Bahasa Indonesia, Desain Instruksional terdiri dari 2 kata, desain yang berarti rancangan sedangkan instruksional mengandung pelajaran (petunjuk, penerangan) Berdasarkan dari pengertian tersebut dapat ditarik kesimpulan bahwa desain instruksional adalah sebuah rancangan sistematik untuk menghasilkan suatu sistem instruksional yang siap digunakan merupakan proses yang panjang.

Suparman berpendapat dalam bukunya yang berjudul "Desain Instruksional Modern" tahun 2012 yang menyatakan bahwa desain Instruksional adalah salah satu wujud penerapan pendekatan sistem dalam kegiatan instruksional wujud lain yang setara dengannya adalah produksi dan penggunaan media instruksional, evaluasi instruksional, dan pengelolaan instruksional" (Suparman.A, 2012:34)

Berdasarkan pada definisi di atas, Desain intruksional dapat artikan sebagai suatu siklus dalam sistem instruksional keseluruhan yang berisi analisa pembelajaran kegiatan sampai evaluasi pembelajaran.

\section{E-Learning}

E-Learning merupakan pembelajaran yang memanfaatkan teknologi informasi dan komunikasi untuk mengelola pembelajaran, mulai dari pemberian materi, pengumpulan tugas dan melihat nilai. ELearning juga dapat dimanfaatkan dalam pembelajaran jarak jauh.

Pendapat di atas diperkuat Darmawan dalam bukunya mengemukakan bahwa $E$ Learning merupakan aplikasi internet yang dapat menghubungkan antara pengajar dan pembelajar dalam sebuah ruang belajar Online. (Darmawan, 2014:10) 
"E-Learning sebagai perintah yang disampaikan dalam perangkat digital seperti komputer atau perangkat mobile yang dimaksudkan untuk mendukung proses pembelajaran."(Clark \& Mayer, 2011:8) Berdasarkan pendapat para ahli mengenai pengertian E-Learning dapat disimpulkan bahwa E-Learning adalah pemanfaatan teknologi untuk proses pembelajaran yaitu berupa kegiatan pembelajaran menggunakan media elektronik yang digunakan secara mandiri oleh mahasiswa.

\section{PTM/Jalan Raya}

Mata kuliah Jalan Raya dan Pemindahan Tanah Mekanis (PTM), terdiri dari dua materi umum tentang Jalan Raya dan PTM. Pada bagian Jalan Raya diberikan materi umum mengenai perencanaan dan desain geometrik jalan, sedangkan pada bagian PTM diberikan materi mengenai perencanaan, analisis dan desain pembangunan jalan berikut peralatannya.

Relevansi Matri ajar Mata Kuliah Jurusan di Prodi PTB FT UNJ dengan Materi Ajar di SMK Program Keahlian Teknik Bangunan.

Materi ajar Mata Kuliah Prodi dikatakan relevan dengan Materi ajar di SMK Program Keahian Teknik Bangunan, apabila ditemukan adanya kecocokan atau keterpautan antara materi pokok dalam Mata Kuliah Jurusan dengan Materi ajar di SMK dan semuanya salaing berkesinambungan serta dapat tercapainya tujuan dari pembelajaran yang sebenarnya.

\section{Tujuan Penelitian}

Tujuan dari penelitian ini adalah untuk menghasilkan pembelajaran ELearning PTM/Jalan Raya di PVKB FT UNJ

\section{Metode Penelitian}

Berdasarkan tujuan dari penelitian ini, jenis penelitian ini adalah penelitian dan pengembangan (Research and Development)
Sukmadinata mengemukakan bahwa penelitian dan pengembangan (R\&D) merupakan pendekatan penelitian untuk menghasilkan produk baru atau menyempurnakan produk yang telah ada.(Sukmadinata \& Syaodih, 2008:23)) pengembangan mengacu kepada model pengembangan Borg and Gall.

Pengumpulan data dan informasi berupa data yang diperoleh dari instrumen berupa data kualitatif dan kuantiatif. Data kualitatif berupa penilaian saran dan kritik dari para ahli instruksional, ahli media dan ahli materi ataupun mahasiswa, data kuantitatif adalah skor penialain angket/kuesioner data yang di analisis merupakan hasil respon dari mahasiswa terhadap produk pembelajaran E-Learning PTM/Jalan Raya.

Teknik Pengumpulan data merupakan suatu cara yang digunakan untuk memperoleh data penelitian, karena tujuan utama dari penelitian adalah mendapatkan data. Metode pengumpulan data yang dilakukan oleh peneliti adalah kuesionar (angket).

"Kuesioner merupakan teknik pengumpulan data yang dilakukan dengan cara memberi seperangkat pertanyaan atau pernyataan tertulis kepada responden untuk dijawabnya"(Sugiyono, 2014:99) Kuesioner ini bertujuan untuk mengetahui tingkat kelayakan produk dari aspek materi dan aspek media, serta untuk mengetahui penilaian dari mahasiswa.

\section{Pembahasan Hasil Penelitian}

Hasil pembahasan dari penelitian ini adalah pembelajaran E-Learning PTM/Jalan Raya dapat dikembangkan dan diterapkan sebagai variasi pembelajaran dalam mata kuliah PTM/Jalan Raya. Pengembangan E-Learning ini telah sesuai dengan hasil kuesioner dan saran dari ahli materi oleh dosen PTM/Jalan Raya UNJ, ahli instruksional dan ahli media oleh dosen teknologi pendidikan UNJ, serta tanggapan dari mahasiswa tentang hasil pembelajaran ELearning pada mata kuliah PTM/Jalan Raya 
Berdasarkan hasil penilaian validasi ahli instruksional, ahli media dan ahli materi dapat disimpulkan bahwa ahli instruksional memberikan penilaian mengenai aspek pembelajaran, materi/kurikulum, aspek tammpilan, aspek program dan aspek bahasa komunikasi didapat hasil 2.5 yang berarti layak karena mendapat nilai minimum 2,50 $\leqslant$. Aspek yang menjadi kekurangan yaitu pada aspek pembelajaran dan aspek program ahli instruksional menyebutkan pada pembelajaran kelengkapan penjelasan singkat pada pendahuluan tambahkan, kesesuaian metode dengan tujuan pembelajaran dianalisis sesuai kebutuhan serta kesesuaian media dengan karakteristik mahasiswa. Pada aspek program ahli instruksional menekankan pada kecukupan tools yang disediakan belum memenuhi kebutuhan belajar, penggunaan hyperlink pada pembelajaran perlu ditambahkan.

Ahli media menilai aspek teks, kombinasi warna, anmasi, tombol navigasi, petunjuk penggunaaan serta implementasi didapatkan hasil total nilai 0,86 yang berarti Layak karena nilai diatas $>0,75$. Aspek yang menjadi perhatian bagi ahli media yaitu aspek teks dan aspek petunjuk penggunaan, pada aspek ahli media menekankan untuk menggunakan ukuran huruf yang lebih besar agar dapat terbaca dengan jelas, pada aspek petunjuk ahli media menyampaikan bahwa dirancang lebih rinci untuk petunjuk produk pembelajaran E-Learning.

Ahli materi memberikan penilaian mengenai aspek tujuan pembelajaran, aspek penampilan materi dan aspek pemilihan materi. Setelah penilaian didapat total hasil yaitu 0,84 yang berarti untuk materi disimpulkan Layak karena nilai di atas dari $>0,75$. Ahli materi memberi beberapa saran untuk materi PTM/Jalan Raya yaitu ditambahkan sumber pada setiap materi untuk memperjelas dasar acuan materi, materi dibuat lebih mudah dipahami dengan memberikan contoh gambar atau kasus yang lebih sederhana.

Berdasarkan validasi dari 3 ahli yaitu ahli instruksional, ahli media dan ahli materi didapat tiga penilaian kelayakan produk pembelajaran E-Learning untuk menentukan pembelajaran E-Learning PTM/Jalan Raya layak digunakan atau tidak layak. Ahli instruksional menilai pembelajaran E-Learning ini mendapat skor minimum kelayakan disimpulkan bahwa Layak dengan catatan masih membutuhkan beberapa revisi, selanjutnya melihat dari penilaian ahli media dan ahli materi, ahli media menyimpulkan bahwa pembelajaran E-Learning Layak, ahli materi juga menyimpulkan bahwa pembelajaran ELearning ini Layak digunakan oleh mahasiswa. Mengacu atas dasar penilaian tersebut dapat disimpulkan bahawa pembelajaran E-Learning layak digunakan mahasiswa PTM/Jalan Raya

E-Learning diperbaiki sesuai dengan masukan dan penilaian dari ahli, maka dilakukannya uji coba penggunaan ELearning dalam kegiatan pembelajaran kepada mahasiswa yang mengambil mata kuliah PTM/Jalan Raya semester 108 tahun akademik 2017/2018. Proses uji coba ELearning ini dengan cara memberikan domain link E-Learning yang telah dibuat lalu mahasiswa login terlebih dahulu, setelah itu mahasiswa harus membaca materi yang telah tersedia pada site home E-Learning PTM/Jalan Raya, ketika mahasiswa telah selesai membaca materi yang telah dianjurkan maka mahasiswa mengisi tes formatif yang telah tersedia untuk mengukur pengetahuan kognitif setelah membaca materi yang sudah tersedia pada site home tersebut.

Mahasiswa langsung mengetahui hasil tes formatif yang sudah mereka kerjakan dan mengisi lembar penilaian terhadap pengembangan E-Learning PTM/Jalan Raya tersebut. Mahasiswa menunjukan motivasi yang lebih saat melaksanakan kegiatan pembelajaran E-Learning. Hal ini sesuai dengan Harandi dalam jurnalnya bahwa

"Siswa lebih cenderung termotivasi ketika menerapkan E-Learning Jika siswa lebih termotivasi untuk belajar, maka mereka lebih mungkin untuk terlibat; dan jika mereka terlibat dan terlibat dengan sukses, 
mereka lebih mungkin untuk mencapai tujuan pembelajaran"(Harandi, 2015:429)

Berdasarkan hasil uji coba mahasiswa pada kegiatan pembelajaran 13, rentang nilai yang didapat oleh mahasiswa yang menggunakan E-Learning mendaptkan nilai sebesar 90. Hasil dari uji coba mahasiswa dapat diartikan diduga bahwa mahasiswa lebih mudah memahami materi PTM/Jalan Raya dengan adanya sistem pembelajaran $E$ Learning. E-Learning akan diuntungkan untuk meningkatkan hasil belajar siswa dan untuk menyediakan teknik pendidikan yang lebih baik (Hussein, 2017:163)

Mahasiswa dapat mempelajari secara mandiri E-Learning tersebut, dalam artian mahasiswa dapat menggunakan E-Learning dimana saja dan kapan saja selama mahasiswa memiliki perangkat berupa komputer atau laptop. E-Learning tersebut dirancang dengan menarik dan didesain dengan memudahkan pengguna dalam penggunaannya. Metode perencanaan menggunakan komperhensif Tahapan pengembangan E-Learning dapat lebih terarah baik dari sisi strategis dan sisi taktis (Supradono, Teknik, Fakultas, \& Semarang, n.d.). Oleh karena itu, E-Learning PTM/Jalan Raya ini menggunakan perencanaan komperhensif.

E-Learning dikembangkan dan digunakan sebagai variasi pembelajaran dalam mata kuliah PTM/Jalan Raya Karena semakin banyak lembaga mengadopsi strategi $E$ Learning, keberhasilan mereka tidak hanya bergantung pada ketersediaan teknologi tetapi juga sejauh mana fakultas dan mahasiswa didukung ketika mereka mengeksplorasi dan mengembangkan caracara inovatif untuk mengintegrasikan teknologi ke dalam pengalaman belajar (Tîrziu, 2015:277)

\section{Kesimpulan}

Berdasarkan hasil penelitian, mulai dari kegiatan validasi E-Learning oleh para ahli, dan melakukan kegiatan uji coba kepada mahasiswa dapat disimpulkan bahwa hasil pengembangan E-Learning
PTM/Jalan Raya berupa produk dapat digunakan sebagai variasi pembelajaran dalam pembelajaran PTM/Jalan Raya Hasil validasi yang diperoleh dari ahli materi Instruksional, ahli media dan ahli materi menyatakan layak.

\section{Implikasi}

Pada penelitian pengembangan E-Learning ini terdapat beberapa implikasi

1. Pembelajaran E-Learning dapat digunakan pada mata kuliah PTM/Jalan Raya

2. Pembelajaran E-Learning ini dapat dilanjutkan pada tahap uji efektifitas produk sebagai pembelajaran E-Learning PTM/Jalan Raya

\section{Saran}

E-Learning mata kuliah PTM/Jalan Raya yang telah dikembangkan, dapat menjadi saran atau masukkan seperti:

1. Untuk mengikuti pembelajaran ELearning dengan baik sebaiknya menggunakan Komputer/Laptop.

2. Koneksi internet stabil saat menjalankan E-Learning untuk membuat akses ELearning lebih cepat

3. Perlunya penerapan E-Llearning pada mata kuliah PTM/Jalan Raya

4. Melakukan tahap selanjutnya yaitu berupa tindakan kelas untuk menguji keefektifan E-Learning PTM/Jalan Raya tersebut.

\section{Daftar Pustaka}

Andreicheva, L., \& Latypov, R. (2015). Design Of E-Learning System : M-Learning Component. Procedia - Social and Behavioral Sciences, 191, 628-633. https://doi.org/10.1016/j.sbspro.2015.04. 580

Clark, R. ., \& Mayer, R. . (2011). E-Learning and the Science of Instruction. San Fransisco: Pfeiffer. 
Darmawan, D. (2014). Pengembangan E-Learning: Teori dan Desain. Bandung: PT. Remaja Rosdakarya.

Daryanto. (2011). Media Pembelajaran. Yogyakarta: Gaya Media.

Goyal, S. (2012). E-Learning : Future of Education, 6, 239-242.

Harandi, S. R. (2015). Effects of E-Learning on students 'motivation. Procedia - Social and Behavioral Sciences, 181, 423-430.

https://doi.org/10.1016/j.sbspro.2015.04. 905

Hussein, Z. (2017). Leading to Intention: The Role of Attitude in Relation to Technology Acceptance Model in ELearning. Procedia - Procedia Computer Science, 105(December 2016), 159-164. https://doi.org/10.1016/j.procs.2017.01.1 96

Srivastava, B., \& Haider, T. U. (2017).

Personalized assessment model for alphabets learning with learning objects in E-Learning environment for dyslexia. Journal of King Saud University - Computer and Information Sciences. https://doi.org/10.1016/j.jksuci.2017.11. 005

Sugiyono. (2014). Metode Penelitian Pendidikan. Bandung: PT.Tarsito.

Sukmadinata, \& Syaodih, N. (2008). Metode Penelitian Pendidikan. Bandung: PT. Remaja Rosdakarya.

Suparman.A. (2012). Desain Instruksional Modern. Jakarta: Erlangga.

Supradono, B., Teknik, J., Fakultas, E., \& Semarang, U. M. (n.d.).

PERANCANGAN PENGEMBANGAN

KOMPREHENSIF SISTEM

PEMBELAJARAN JARAK JAUH (

DISTANCE LEARNING ) DI

INSTITUSI PERGURUAN TINGGI

YANG, 31-36.

Tîrziu, A.-M. (2015). Education 2 . 0 : E-

Learning Methods, 186, 376-380.

https://doi.org/10.1016/j.sbspro.2015.04.

213 